\title{
LOW-CYCLIC FATIGUE OF POLYMERIC COMPOSITE FILLED WITH BIOLOGICAL SHORT FIBRES
}

\author{
Vladimir Sleger, Miroslav Muller \\ Czech University of Life Sciences Prague \\ sleger@tf.czu.cz,muller@tf.czu.cz
}

\begin{abstract}
The paper deals with a research of utilization of natural fibres of the plant Ensete ventricosum in an area of polymeric composites. A low-cyclic fatigue of composite materials was tested at composites with 1,2, 3, 4 and 5 vol. \% of filler in a form of short fibres 1 to $3 \mathrm{~mm}$ and 3 to $5 \mathrm{~mm}$. They are short-fibre non-oriented composites with L/D 11.05 and 22.50. A structural epoxy resin ChS Epoxy 1200/324, so called reactoplastics, was a matrix. Smaller values of the loading $(15 \%)$ at the cyclic tests have not a significant influence on the resultant strength of the polymeric composite filled with biological short fibres of the plant Ensete ventricosum. The lengths of Ensete ventricosum fibres used as the reinforcement of the polymeric composite 1 to $3 \mathrm{~mm}$ and 3 to $5 \mathrm{~mm}$ have not a statistically significant influence on the strength of the composite material after 200 cycles at the concentrations 1,2 and 3 vol. $\%$. The influence of the length was proved to the concentration 5 vol. $\%$.
\end{abstract}

Keywords: cyclic test, tensile strength, epoxy resin, natural fibres, concentration.

\section{Introduction}

Requirements are put on decrease of the mass of a construction and utilization of a biological component in the construction of automobiles, agricultural machines [1;2] etc. This requirement is secured namely by the use of polymeric composites based on a biological reinforcement or a matrix. One of the possible directions of the use of natural materials is application of natural fibres as the reinforcement in composite materials [1;3; 4]. The composite material reinforced with Ensete fibres could be used for the production of parts for the automotive industry [1]. Polymers are important matrix materials for forming advanced composites. The reinforcing materials in advanced composites take many forms. In addition to continuous fibres, many types of short reinforcing elements are used in composites [5].

The paper deals with the research of the utilization of natural fibres of the plant Ensete ventricosum in the area of polymeric composites. Fibres were delivered within cooperation with the Faculty of Industrial Technologies in Púchov, which has been dealing with the textile research for a long time. The application of natural fibres in a form of reinforcement in the area of composites is their possible utilization [6]. Composites based on natural fibres are materials, which provide new possibilities in development of technical materials $[7 ; 8]$. They are renewable raw materials which are distinguished for good mechanical properties. An essential change of mechanical properties of the composite materials is possible to reach by adding an optimum volume, i.e. the reinforcement [9-13]. Not only basic mechanical properties but also behaviour of given material at the practical application are important for practical application [7]. The practical application can be simulated by cyclic loading $[14 ; 15]$. At present, there is a trend to replace synthetic fibres with natural ones $[7 ; 8]$.

The aim of the experiments is to clarify fatigue behaviour of the polymeric composite filled with biological short fibres. The aim of the research was to evaluate the influence of various concentrations and lengths of biological short fibres Ensete ventricosum on the low-cyclic fatigue of the composite materials.

Many authors dealt with the research in natural fibres of the plant Ensete ventricosum $[1 ; 2 ; 6-8]$. These researches dealt with mechanical properties of fibres, their treatment by plasma or their utilization in the area of polymeric composite materials. The research in low-cyclic fatigue of the polymeric composite filled with biological short fibres of Ensete ventricosum was not performed in any study. This research is essential in terms of the practical application of the composite system.

\section{Materials and methods}

The low-cyclic fatigue of the polymeric composite filled with biological short fibres was tested on test samples made according to the standard CSN EN ISO 3167 (Plastics - Multipurpose test specimens, Czech Standard Institution). The tested samples can be seen in Fig. 1. 
The low-cyclic fatigue of composite materials was tested at the composites with 1, 2, 3, 4 and 5 vol. \% of the filler in the form of short fibres 1 to $3 \mathrm{~mm}$ and 3 to $5 \mathrm{~mm}$. The size of the short fibres is shown in Fig. $1 \mathrm{C}$ and D. They are short-fibre non-oriented composites with $L / D 11.05$ and 22.50. Structural epoxy resin ChS Epoxy 1200/324, so called reactoplastics, was the matrix.
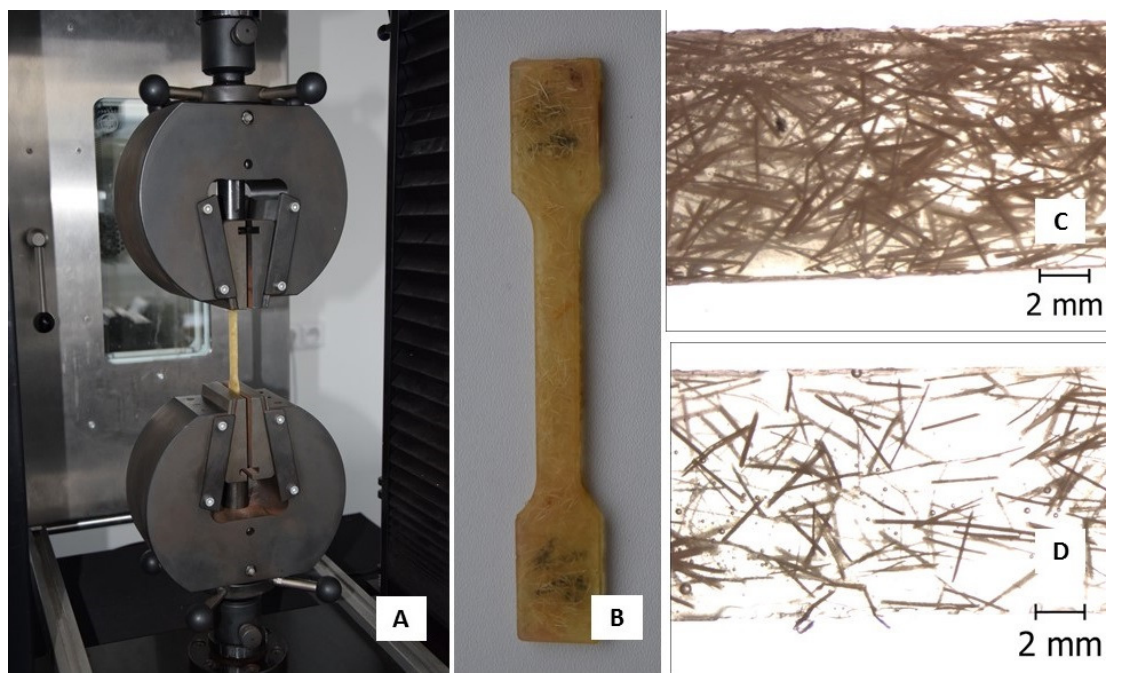

Fig. 1. Test sample - Tensile strength: A: testing of samples in LABTest 5.50ST; B: test sample according to the standard CSN EN ISO 3167; C: polymeric composite filled with biological short

fibres with 5 vol. \%; D: polymeric composite filled with biological short fibres with 1 vol. \%

Representation of the lengths cut by means of a special knife Morakniv in the series 1 to $3 \mathrm{~mm}$ $(1.96 \pm 0.57 \mathrm{~mm})$ and 3 to $5 \mathrm{~mm}(4.19 \pm 0.32 \mathrm{~mm})$ is shown in Fig. 2 . The fibres in the interval 1 to $3 \mathrm{~mm}$ showed higher variability. The mean of fibres in the series 1 to $3 \mathrm{~mm}$ was $178 \pm 16 \mu \mathrm{m}$ and in the series 3 to $5 \mathrm{~mm} 186 \pm 8 \mu \mathrm{m}$.

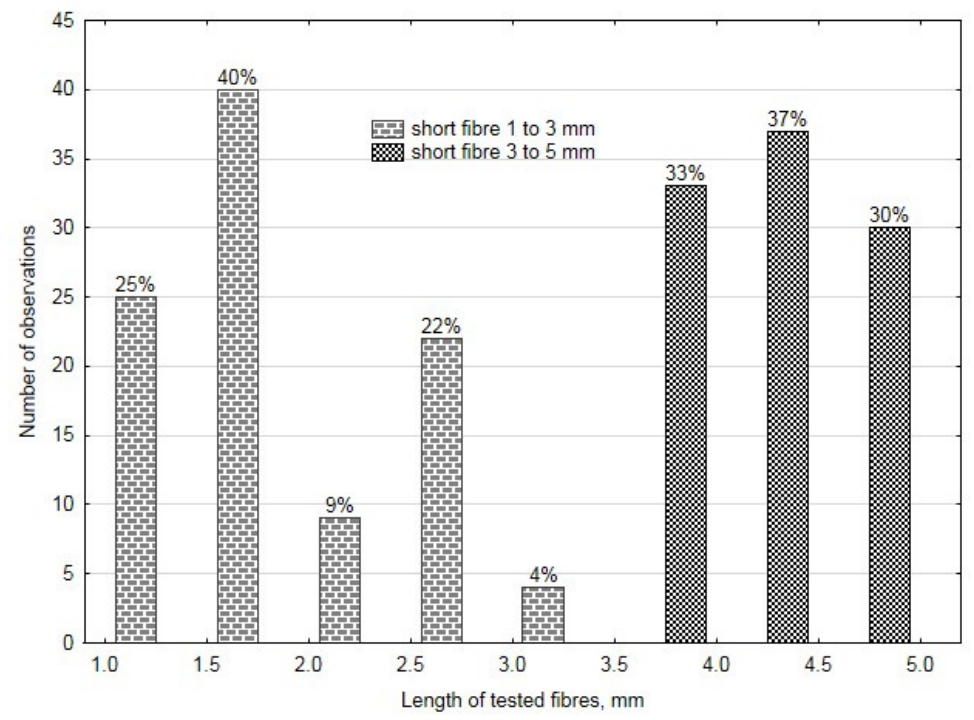

Fig. 2. Histogram - length of fibres used in composite material

By mixing of the specified matrix - short fibres ratio the composite was made, which was used for preparation of the test samples according to the specified standards. The moulds for casting were made from the material Lukapren $\mathrm{N}$ using models. The form and size of the moulds meet the corresponding standards CSN EN ISO 3167. The test sample was kept with the laboratory temperature $22 \pm 2{ }^{\circ} \mathrm{C}$ for $72 \mathrm{hr}$ hardening. Laboratory tests were performed using the universal tensile strength testing machine LABTest 5.50ST (a sensing unit AST type KAF $50 \mathrm{kN}$, evaluating software Test\&Motion). The created composites were tested for 200 cycles, among $3 \%$ to $15 \%$ of a mean of the maximum force (cca $1650 \mathrm{~N}$ ), at the static test (matrix, reactoplastics) by the speed $20 \mathrm{~mm} \cdot \mathrm{min}^{-1}$ with a stamina $0.5 \mathrm{~s}$ at the minimum as well as the maximum force. A destructive testing was 
performed after finishing 200 cycles by the speed $2 \mathrm{~mm} \cdot \mathrm{min}^{-1}$ (the same as at the static tensile test). All tested materials resisted to 200 tested cycles.

The results of measuring were statistically analysed. Statistical hypotheses were also tested at the measured sets of data by means of the program STATISTICA (Anova F-test). A validity of the zero hypothesis $\left(\mathrm{H}_{0}\right)$ shows that there is no statistically significant difference $(p>0.05)$ among the tested sets of data. Whether the sets are homogeneous or not is determined according to the parameter $\mathrm{p}$, which confirms or disproves the statistical hypothesis. The results of the statistical evaluation are worked in the text. An optical analysis by means of a stereoscopic microscope Arsenal and SEM by means of Tescan Mira 3 GXM was used for the research of the length and the width of fibres and the fracture surface.

\section{Results and discussion}

The tensile strength of the matrix (resin, without the reinforcing phase) was ca. $44 \mathrm{MPa}$. The tensile strength of the matrix after 200 cycles was $38 \mathrm{MPa}$. The influence of the concentration of the polymeric composite filled with biological short fibres on the tensile strength after 200 cycles is skown in Fig. 3.

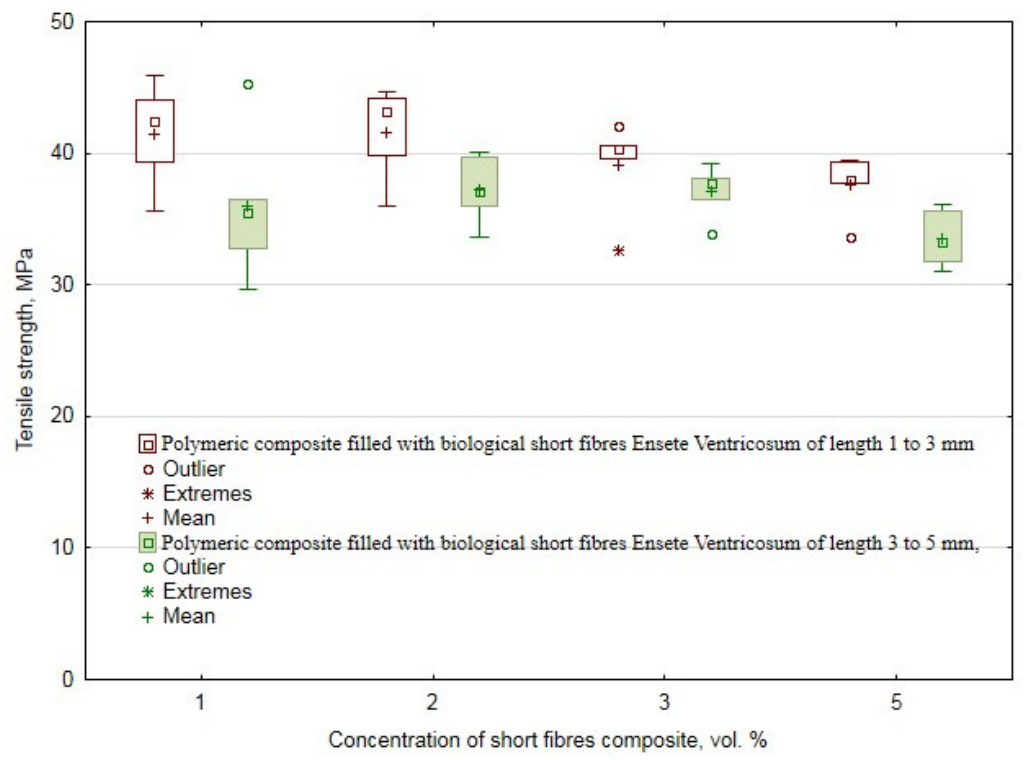

Fig. 3. Influence of concentration of polymeric composite filled with biological short fibres on tensile strength

It is possible to say in terms of the statistical testing of the influence of the volume concentrations of the fibres Ensete ventricosum used as the reinforcement of the polymeric composite that they are statistically homogeneous groups, i.e. there is no difference in the volume concentrations $1,2,3$ and $5 \%$ on the strength of the composite material after 200 cycles. The hypothesis $\mathrm{H}_{0}$ was certified, i.e. there is no difference among single tested sets in the significance level 0.05, i.e. $p>0.05$, short fibres in the length interval 1 to $3 \mathrm{~mm} p=0.2492$, short fibres in the length interval 3 to $5 \mathrm{~mm} p=0.3605$. The difference in the tested concentrations of fibres used as the reinforcing phase was not statistically proved.

It is possible to say in terms of the statistical testing of the influence of various lengths of the reinforcing fibres of Ensete ventricosum on the strength of the composite material after 200 cycles at 1,2 and 3 vol. \% that the lengths are statistically homogeneous groups, i.e. there is no difference between the lengths 1 to $3 \mathrm{~mm}$ and 3 to $5 \mathrm{~mm}$. The hypothesis $\mathrm{H}_{0}$ was certified, i.e. there is no difference among single tested sets in the significance level $0.05, p>0.05$, for the concentration 1 vol. $\% p=0.1216,2$ vol. $\% p=0.0660,3$ vol. $\% p=0.3184$. The difference in the tested lengths was not statistically proved.

The influence of the difference of the reinforcing fibres lengths was statistically proved at the highest concentration 5 vol. $\%(p=0.0233)$. 
The course of the matrix (i.e. resin) behaviour is visible from the diagram of the tensile strength test (Fig. 4). It is reactoplastics without a significant yield point. The course of the testing of the polymeric composite filled with biological short fibres at various concentrations and lengths of the fibres is visible from the diagram of the low-cyclic test of the tensile strength (Fig. 5 to 6). Fig. 5 to 6 present the low-cyclic tensile strength test at $15 \%$ maximum force reached at the matrix at the static tensile test, which is finished by destruction of the composite material after reaching 200 cycles.

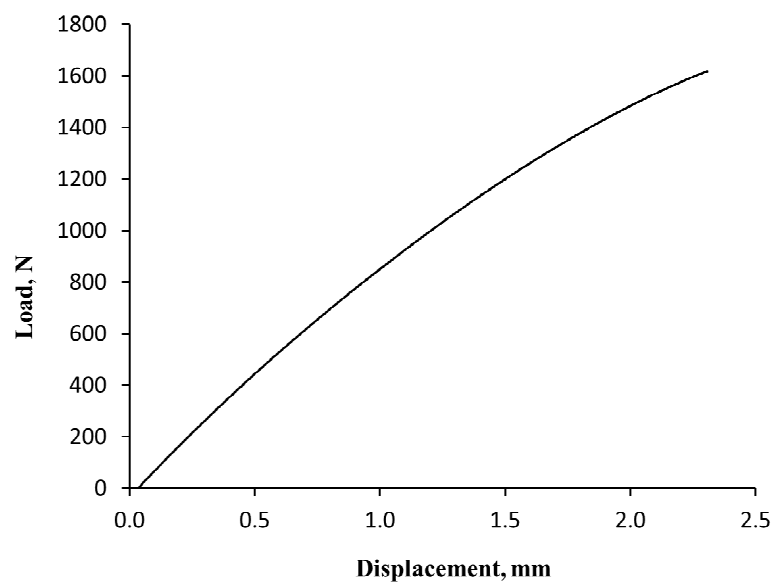

Fig. 4. Tensile diagram of matrix
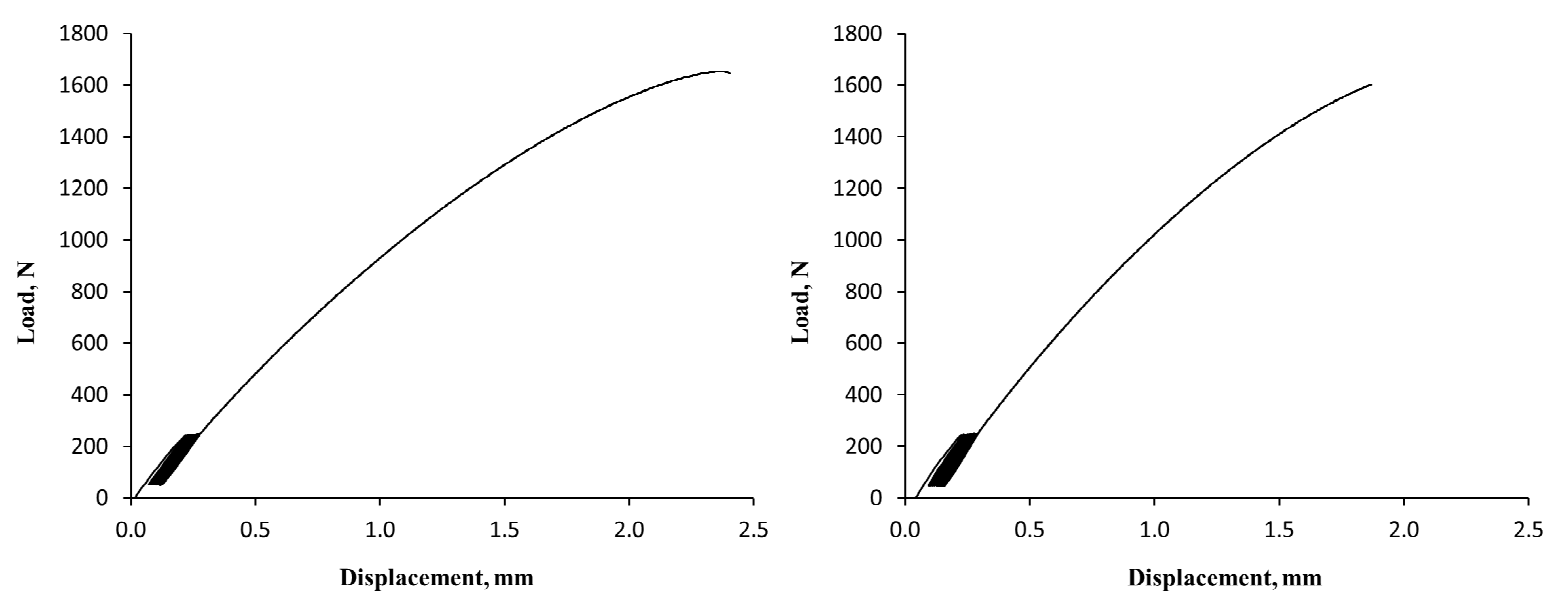

Fig. 5. Low-cyclic test of polymeric composite filled with biological short fibres 1 to $3 \mathbf{m m}$, 200 cycles: left: 1 vol. $\%$; right: 5 vol. \%
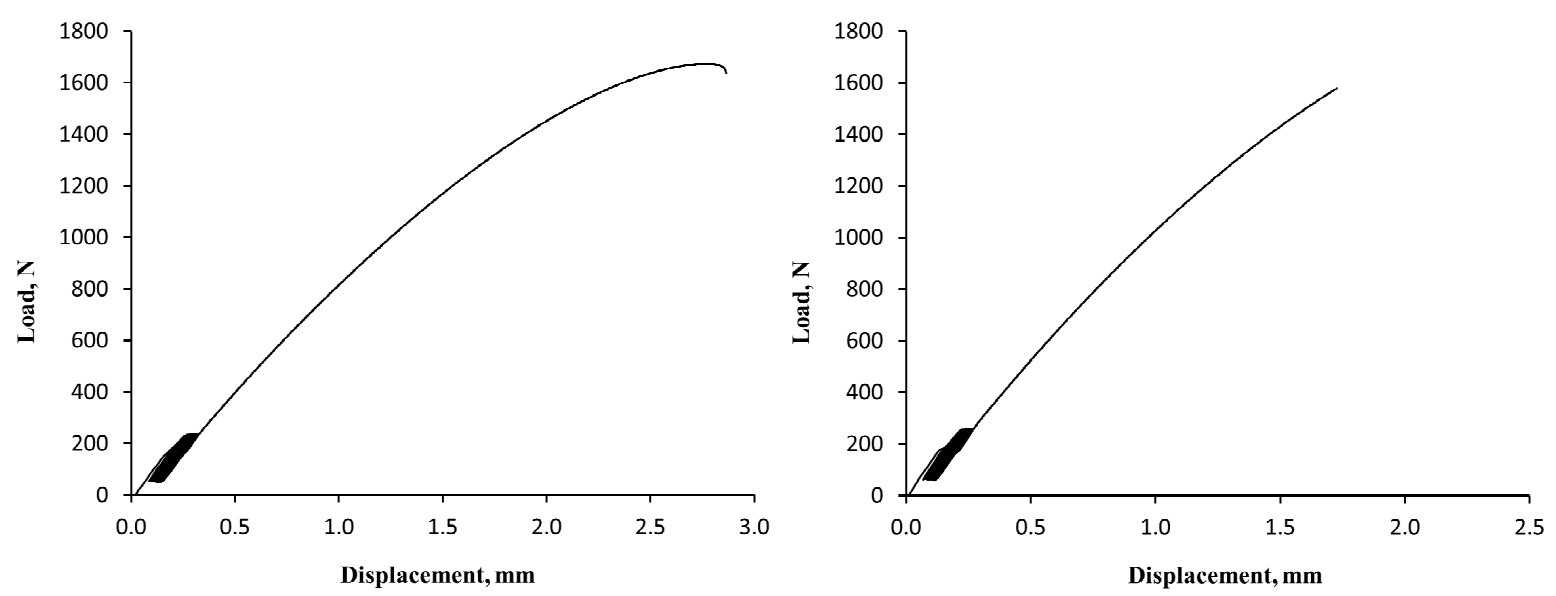

Fig. 6. Low-cyclic test of polymeric composite filled with biological short fibres 3 to $5 \mathbf{m m}$, 200 cycles: left: 1 vol. \%; right: 5 vol. $\%$ 
The good wettability of the biological short fibres of Ensete ventricosum with the adhesive (the matrix) was proved by the use of electron microscopy within the experimental research (Fig. 7 A), although the surface of the fibres was not treated (chemically nor by plasma) before their application into the composite material (Fig. 7 B).
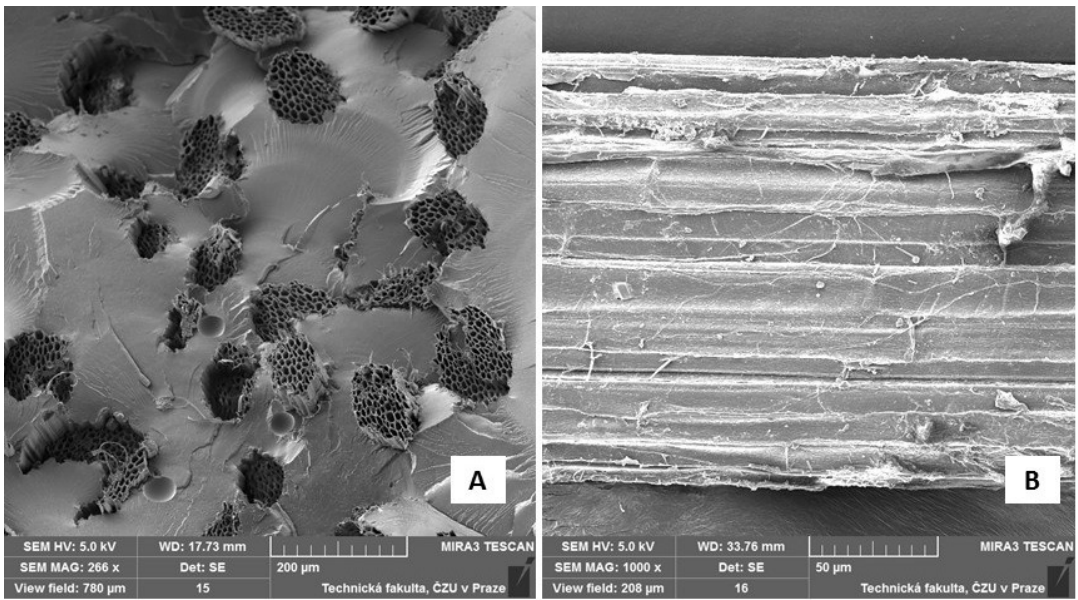

Fig. 7. SEM images: A: polymeric composite filled with biological short fibres (5 vol. \%, 1 to $3 \mathrm{~mm}$, MAG $266 \mathrm{x}$ ); B: surface of fibres of plant Ensete ventricosum (MAG $1000 \mathrm{x}$ )

Natural fibres such as jute, kenaf, hemp, sisal, flax, bagasse etc. are successfully used as the reinforcement in the polymeric composites [7; 16-22]. It is desirable to integrate renewable resources in the area of the material engineering [7].

Short fibre composites are used above all in application where it is not possible to determine exactly in advance the effects of the loading or the loading is approximately the same in all directions [7]. Further, the short fibre composites are applied where there are requirements for easy workability and good mechanical properties [23;24].

The strength fall but the increase of the modulus of elasticity and the impact strength occur by the use of the fibres of the plant Ensete ventricosum in the area of polymeric composites [7]. This conclusion was certified when evaluating the tensile strength.

The application of polymers (adhesives, liquid metals) is limited by the cyclic loading [25]. The experiment results did not prove a basic influence of the low-cyclic fatigue of the polymeric composite filled with biological short fibres.

The assumption that the repeated cyclic loading with the low value (i.e., e.g. $15 \%$ from the reference tensile strength of the matrix) can lead to premature failure of the adhesive bond in the relatively short number of cycles was not certified by the experiment results. Analogous results were also reached at the adhesive bond testing [26;27].

Service conditions can often involve the exposure to the cyclic fatigue, which is possibly the most destructive form of mechanical loading. The fatigue damage is an irreversible process that can occur at relatively low stress levels due to the presence of high peel and shear stresses at the overlap edges. These stresses reduce both the static strength and the fatigue life of bonded structures [26].

The above mentioned can influence the integrity of the adhesive bonds, the polymeric composites. The reason is a possibility of crack origin, which can influence the service life of the polymer. From this reason it is essential to test the polymeric materials (composites) to combined loading, which occurs at practical application [28].

Low values of loading at the cyclic tests do not have a significant influence on the resultant strength of the reactoplastics (adhesives) [27]. Analogous trend occurred at the polymeric composite filled with biological short fibres of the plant Ensete Ventricosum.

The SEM analysis proved good wettability of the reinforcement with the matrix. This assumption is important for reaching good wettability [29]. 


\section{Conclusions}

The aim of the experiment was to clarify the low-cyclic fatigue behaviour of the polymeric composite filled with biological short fibres of the plant Ensete ventricosum at various concentrations and lengths of the fibres. The following conclusions can be deduced from the results:

- The volume concentrations 1,2,3 and 5 vol. \% of Ensete ventricosum used as the reinforcement of the polymeric composite have not statistically significant influence on the strength of the composite material after 200 cycles.

- The lengths of Ensete ventricosum fibres used as the reinforcement of the polymeric composite 1 to $3 \mathrm{~mm}$ and 3 to $5 \mathrm{~mm}$ have not a statistically significant influence on the strength of the composite material after 200 cycles at the concentrations 1, 2 and 3 vol. \%. The influence of the length was proved to the concentration $5 \mathrm{vol} . \%$. The difference of the strength of the composite material was $10 \%$ on average depending on the length of the reinforcing fibres.

- Smaller values of the loading $(15 \%)$ at the cyclic tests have not a significant influence on the resultant strength of the polymeric composite filled with biological short fibres of the plant Ensete Ventricosum.

- Good wettability between the adhesive (the matrix) and biological short fibres of the plant Ensete ventricosum was proved by the use of electron microscopy within the experimental research although the surface of the fibres was not chemically nor mechanically treated before their application in the composite material.

\section{Acknowledgement}

Supported by Internal grant agency of the Faculty of Engineering, Czech University of Life Sciences in Prague.

\section{References}

1. Mizera C., Hrabe P., Muller M., Herak D. Creep behaviour of the polymer composite with false banana's fibres (Ensete Ventricosum). Manufacturing Technology, vol. 16(1), 2016, pp. 188-192.

2. Mizera C., Herak D., Hrabe P., Muller M. Kabutey A. Mechanical Behavior of Ensete ventricosum Fiber Under Tension Loading. Journal of Natural Fibers, vol. 14(2), 2017, pp. 287296.

3. Poole A.J., Church J.S., Huson M.G. Environmentally sustainable fibers from regenerated Protein. Biomacromolecules, vol. 10, 2009, pp. 1-8.

4. Wambua P., Ivens J., Verpoest I. Natural fibres: can they replace glass in fibre reinforced plastics? Composites Science and Technology, vol. 63, 2003, pp. 1259-1264.

5. Cho J., Joshi M.S., Sun C.T. Effect of inclusion size on mechanical properties of polymeric composites with micro and nano particles. Composites Science and Technology, vol. 66, 2006, pp. 1941-1952.

6. Hrabe P., Muller M., Mizera C. The effect of plasma treatment on tensile strength of Ensete ventricosum fibres. Manufacturing Technology, vol. 16(5), 2016, pp. 928-933.

7. Muller M., Valasek P., Ruggiero A. Strength characteristics of untreated short-fibre composites from the plant ensete ventricosum. BioResources, vol. 12(1), 2017, pp. 255-269.

8. Mizera C., Herak D., Hrabe P., Muller M., Kabutey A. Effect of Length of False Banana Fibre (Ensete ventricosum) on Mechanical Behaviour under Tensile Loading. Scientia Agriculturae Bohemica, vol. 47(2), 2016, pp. 90-96.

9. Galusek D., Sedlacek J., Riedel R. Al2O3-SiC composites prepared by warm pressing and sintering of an organosilicon polymer-coated alumina powder. Journal of the European Ceramic Society, vol. 27(6), 2007, pp. 2385-2392.

10. Kim H.S., Khamis M.A. Fracture and impact behaviours of hollow micro-sphere/epoxy resin composites. Composites Part A: Applied Science and Manufacturing, vol. 32(9), 2001, pp. 13111317.

11. Agoudjil B., Ibos L., Majeste J.C., Candau Y., Mamunya YE.P. Correlation between transport properties of Ethylene Vinyl Acetate/glass, silver-coated glass spheres composites. Composites Part A: Applied Science and Manufacturing, vol. 39(2), 2008, pp. 342-351. 
12. Muller M., Valasek P. Abrasive wear effect on Polyethylene, Polyamide 6 and polymer particle composites. Manufacturing Technology, vol. 12(12), 2012, pp. 55-59.

13. Valasek P., Muller M. Impact strength of polymer particle composites with filler on the basis of corundum waste. Engineering for Rural Development, May 24-25, 2012, Jelgava, Latvia, pp. 304308.

14. Sleger V., Muller M., Zavrtalek J. Low-cyclic fatigue of adhesive bonds reinforced with fibres. Proceeding of 6th international conference on trends in agricultural engineering 2016, September 7-9, 2016, Prague, Czech Republic, pp. 644-651.

15. Sleger V., Muller M. Low-Cyclic Fatigue of Adhesive Bonds. Manufacturing Technology, vol. 16(5), 2016, pp. 1151-1157.

16. Kakou C.A., Arrakhiz F.Z., Trokourey A., Bouhfid R., Qaiss A., Rodrigue, D. Influence of coupling agent content on the properties of high density polyethylene composites reinforced with oil palm fibers. Materials and Design, vol. 63, 2014, pp. 641-649.

17. Lu X., Zhang M.Q., Rong M.Z., Shi G., Yang, G.C. Self-reinforced melt processable composites of sisal. Composites Science and Technology, vol. 63(2), 2003, pp. 177-186.

18. Zhao X., Li R.K.Y., Bai S.-L. Mechanical properties of sisal fiber reinforced high density polyethylene composites: Effect of fiber content, interfacial compatibilization, and manufacturing process. Composites Part A: Applied Science and Manufacturing, vol. 65, 2014, pp. 169-174

19. Doumbia A.S., Castro M., Jouannet D., Kervoelen A., Falher T., Cauret L., Bourmaud A. Flax/polypropylene composites for lightened structures: Multiscale analysis of process and fibre parameters. Materials and Design, vol. 87, 2015, pp. 331-341.

20. Abdul Nasir A.A., Azmi A.I., Khalil A.N.M. Measurement and optimisation of residual tensile strength and delamination damage of drilled flax fibre reinforced composites. Measurement: Journal of the International Measurement Confederation, vol. 75, 2015, pp. 298-307.

21. Ho M.-P., Wang H., Lee J.-H., Ho C.-K., Lau K.-T., Leng J., Hui D. Critical factors on manufacturing processes of natural fibre composites. Composites Part B: Engineering, vol. 43(8), 2012, pp. 3549-3562.

22. Cheung H.-y., Ho M.-p., Lau K.-t., Cardona F., Hui D. Natural fibre-reinforced composites for bioengineering and environmental engineering applications. Composites Part B: Engineering, vol. 40(7), 2009, pp. 655-663.

23. De S.K., White J.R. Short fibre-polymer composites. Cambridge: Woodhead Publishing, 1996. $260 \mathrm{p}$.

24. Mallick P.K. Particulate and short fiber reinforced polymer composites. Comprehensive Composite Materials, vol. 2, 2000, pp. 291-331.

25. Messler R.W. Joining of materials and structures from pragmatic process to enabling technology. Burlington: Elsevier, 2004. 816 p.

26. Broughton W.R., Mera R.D., Hinopoulos G. Cyclic Fatigue Testing of Adhesive Joints, Test Method Assessment, Project PAJ3 - Combined Cyclic Loadingand Hostile Environments 19961999, Report No 8. Teddington: Centre for Materials Measurement \& Technology, National Physical Laboratory, 1999. 34 p.

27. Sleger V., Muller M. Quasi Static Tests of Adhesive Bonds of Alloy AlCu4Mg. Manufacturing Technology, vol. 15(4), 2015, pp. 694-698.

28. Kelly G. Quasi-static strength and fatigue life of hybrid (bonded/bolted) composite single-lap joints. Composite Structures, vol. 72, 2006, pp. 119-129.

29. Jackel M., Scheibner W. Boundary layer induced modification of thermal and mechanical properties of epoxy resin composites. Cryogenics, vol. 31(4), 1991, pp. 269-272. 